\title{
Autonomous and Environmentally Comfortable Type of Housing for the Development of the Arctic
}

\author{
Sergey I. Bartsev*, Andrey G. Degermendzy, \\ Victor A. Okhonin and Alexander A. Tikhomirov \\ Institute of Biophysics SB RAS \\ FRC "Krasnoyarsk Science Center SB RAS" \\ 50/50 Akademgorodok, Krasnoyarsk, 660036, Russia
}

Received 22.02.2018, received in revised form 19.04.2018, accepted 11.05.2018

Factors that impede the development of the Arctic are: 1) long frosts; 2) low quality of indoor air; 3) an unsanitary surroundings due to low activity of biota; 4) deficiency of fresh vitamin-containing food; 5) high dependency of settlements on external supply. The concept of the Arctic EcologicalEnergy Autonomous Dwelling (AEEAD) designed to solve the problems is grounded on: 1) the optimal configuration of housing and heat savings; 2) closure of the flows of substances; 3) the use of autonomous energy sources.

To ensure energy savings and maintain a high quality of life air revitalization is required. Air revitalization is provided by household greenhouses, which perform additional functions - heating the living quarters, lighting it, moistening the winter overdried air, growing food, decorating house interior, providing psychological support. New technologies for growing a variety of plants and organic wastes decomposition are discussed.

Energetic autonomy is provided by means coupling wind generator with high-heat accumulators based on cheap solid heat-storage materials coupled, in its turn, with Stirling enginelelectrical generator unit. Due to "macro-composite" structure of heat exchanger it can be achieved: almost zero heat loss in the absence of thermal insulation; a significant stabilization of the temperature at the output of the thermal battery, over the whole period of the discharge.

Keywords: optimal Arctic dwelling, arctic life support system, cheap heat accumulator.

Citation: Bartsev S.I., Degermendzy A.G., Okhonin V.A., Tikhomirov A.A. Autonomous and environmentally comfortable type of housing for the development of the Arctic. J. Sib. Fed. Univ. Biol., 2018, 11(2), 190-198. DOI: 10.17516/1997-13890062 .

(c) Siberian Federal University. All rights reserved

* Corresponding author E-mail address: bartsev@yandex.ru 


\title{
Автономный и экологически комфортный тип жилья для освоения Арктики
}

\author{
С.И. Барцев, А.Г. Дегерменджи, \\ В.А. Охонин, А.А. Тихомиров \\ Институт биофизики СО РАН \\ ФИЦ «Красноярский научный центтр СО РАН» \\ Россия, 660036, Красноярск, Академгородок, 50/50
}

Факторами, препятствующими освоению Арктики, являются: 1) длительные морозы; 2) низкое качество воздуха в помещении; 3) антисанитарное состояние около жилищ вследствие низкой активности биоты; 4) дефицит свежей витаминосодержащей пищчи; 5) высокая зависимость поселений от внешних поставок топлива. Концепция Арктического Эколого-Энергетического Автономного Жилья (АЭЭАЖ), разработанная для решения этих проблем, основана на: 1) оптимальной конфигураџии строений и сохранении тепла; 2) частичном замыкании потоков веществ; 3) использовании автономных источников энергии.

Для обеспечения экономии энергии и одновременного поддержания высокого качества жизни требуется ревитализация атмосферы в помещчениях. Ревитализация воздуха обеспечивается бытовыми теплицами, которые выполняют дополнительные функции - нагревают жилье помещуения, освещуают их, увлажняют зимний пересушенныйвоздух, производят растительную пищу, украшают интерьер помещения, создавая благоприятную психологическую обстановку. Обсуждаются новые технологии выращчивания различных растений и разложения органических отходов.

Энергетическая автономия обеспечивается с помощуюю ветрогенератора, сопряженного с высокотемпературным тепловым аккумулятором на основе дешевых природных теплозапасающих материалов, сопряженным, в свою очередь, с двигателем Стирлинга. Из-за «макрокомпозитной» структуры теплообменника может быть достигнута почти нулевая потеря тепла при отсутствии теплоизоляциии и значительная стабилизация температуры на выходе теплового аккумулятора.

Ключевые слова: оптимальное арктическое жилище, арктическая система жизнеобеспечения, дешевый тепловой аккумулятор.

\section{Introduction}

Currently, Arctic becomes a territory with political and economic interests of many countries to be collided (Fedoseev, 2013). Opposite objectives pursued by various (primarily Arctic) states in the Arctic result in international tension growth, in general, thus decreasing the conflicts threshold of a local nature in particular. Conflicts of different nature may bring a serious obstacle to achieve goals in the Arctic region, by Russia.

Therefore, Russia's intention to maintain the development the Arctic is of great importance for economy growth and independence. Russia faces a number of attempts to restrict the activity and leadership in the region, among them are the growth of military presence, economic pressure 
and the promotion of negative public opinion based on environmental arguments. There is no simple response on that challenge. In particular, the expansion in military, industrial, scientific and cultural presence in the region, accounting environmental issues, must be undertaken.

Thus, the proposed concept of an autonomous Arctic eco-energy residential facility allows a long-term independent stay of human crew under polar conditions providing preservation of the intact environment. It will cancel the violations of well-grounded claims on the negative impact of the facilities on the environment. Energy independence is extremely important for extremely low temperatures, ensuring the function of military and industrial infrastructure with respect to possible risks of supply violations.

\section{General concept}

Proper living conditions for inhabitants are crucial for the development of the Arctic. Such living environment will maintain the well-being and high efficiency of the staff for a long time. The factors negatively affecting the life of people in Arctic are:

1) long frosts requiring extended reservations of fuel for heating, that results in;

2) pollution of the environment;

3) low quality of indoor air;

4) sanitary violation risks resulted from the low average annual activity of the biota unable to treat wastes produced by the living facilities;

5) a shortage of fresh vitamin-containing food.

Additionally, the orientation to outer supply of fuel (diesel oil, coal) makes the arctic settlements very sensitive and dependent on external factors: weather, economic situation, and military blockade of transports, etc.
Since non-autochthonous humans are not adapted to arctic environmental conditions, especially in winter, the problem arises to provide the new-comers with proper, sustainable and comfort life. This problem resembles to some extent the similar issue for space crew life support. The experience of the Institute of Biophysics SB RAS in the efficient implementation of life support systems (LSS) for extremely aggressive environment (that is open space) can be applied to resolve the problem. Key issue of the Arctic Ecological-Energy Autonomous Dwelling (AEEAD) stands on:

1) optimal configuration of housing and heat savings;

2) optimal closure of the flows of substances;

3) the usage of local independent energy sources.

Consider them in more detail.

\section{Optimal configuration of housing} and heat savings

Standard architecture of residential buildings is poorly adapted to the environmental conditions of the Arctic (and Siberia, in particular). So the standards of glazing and warming buildings obviously do not correspond to the observed temperature drops. In addition, we are actually hostages of central heating, which betrays the inhabitants when it is most needed. In urban and urban areas, where various industrial plants and factories are located, additional pollution of the air pool and water is added to the adverse natural factors.

World experience of heat conservation in northern houses is already available. In 1973, as a result of a sharp rise of oil prices, sealed dwelling houses and offices with controlled outer air exchange began to be used. Simultaneously the standard of air exchange intensity was changed from 580 to $190 \mathrm{~m}^{3} /($ day*person). 
However, this led to the emergence of the Sick Building Syndrome (SBS), which manifests itself in the number of symptoms: headache, fatigue, drowsiness, difficulty concentrating, stuffy nose, dry cough, irritation of the eyes, nose and throat (Kapfhammer, 2003; Mendell, 1993; Shahzad, 2016; Sick Building Syndrome, 1997; Zweers et al., 1992). These symptoms quickly pass after the person leaves the "sick" room. Consequently, the closure of air in the room and the saturation of modern living quarters with artificial materials emitting harmful substances deaden the air and lead to a significant deterioration of indoor air quality.

The main principle of AEEAD design can be illustrated by simple example. Accepting the norm of living space of $50 \mathrm{~m}^{3}$ per person it is possible to fit the entire population of the city of Norilsk ( $\sim 180000$ people) in a house-ball of $\sim 120$ $m$ radius. Calculations show that this super-house does not require any heating even at the most severe frosts - heat emitted by residents and household appliances is sufficient. So for heat conservation AEEAD have to be of minimum of surface/volume ratio. Calculations, demonstrating the principle are presented on Fig. 1 (regular construction materials were used for the assessment). The last case means that for an apartment of 100 square meters (25 meters in length and 4 meters in width) heat generation of 3-5 people themselves together with heat generation of house equipment is sufficient for normal life even at $40^{\circ} \mathrm{C}$ frost. So the effect of using so called broad dwellings is obvious. We can essentially reduce the problem of heat conservation, but the problem of indoor air quality is steel unresolved. The solution of the problem is closely connected with optimal closing the flows of substances.

\section{Optimal closing the flows of substances}

To ensure energy savings and maintain a high quality of life air revitalization is required. The basis of the system of indoor air revitalization can be the technologies that were used in the closed ecological system BIOS-3 (Fig. 2), developed and tested at the Institute of Biophysics of the SB RAS as a prototype of the lunar base (Gitelzon et al., 1975). It is necessary to note that in the BIOS facility under complete isolation from the atmosphere, the SBS, which is typical for heat-saving dwellings, did not arise (Gitelson, Okladnikov, 1994). Air revitalization in BIOS was provided by household greenhouses. These greenhouses are technological devices that perform combined functions - heating the living quarters, lighting it, moistening the winter overdried air, growing food, decorating house interior, providing psychological support. The

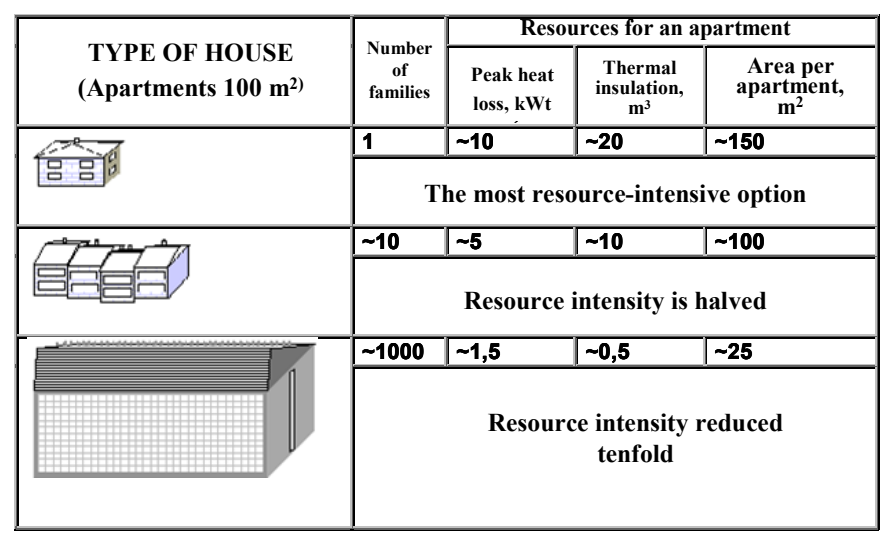

Fig. 1. General view and main parameters of dwellings of different configuration 

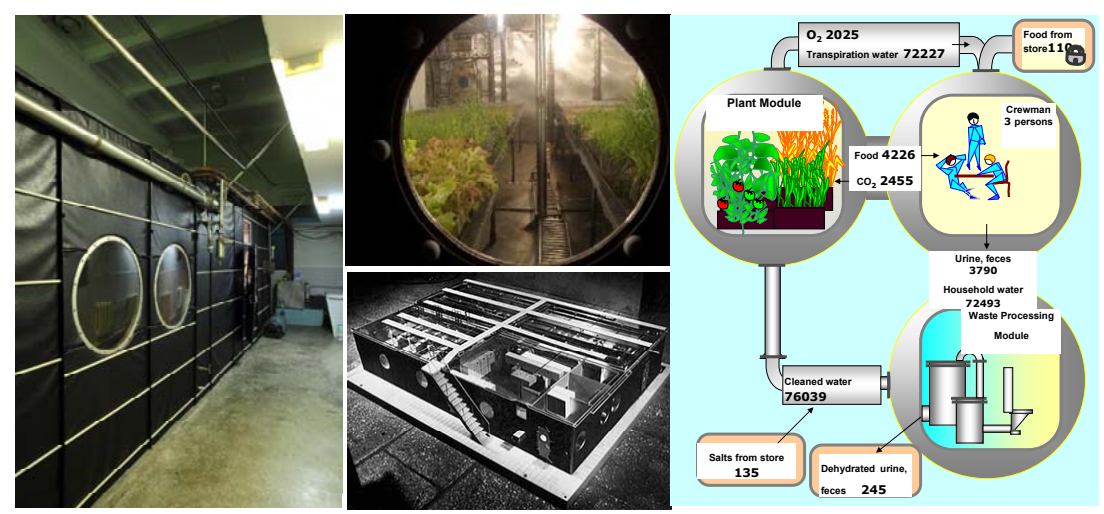

Fig. 2. Side view of BIOS-3 facility (left). The view of the greenhouse through the porthole of BIOS-3 and the layout of it (middle). Simplified layout and general outline of the BIOS-3 (right)

unit for processing organic wastes and partial closure of matter cycles in AEEAD reduce the destructive effect on the environment almost to zero.

Certainly Arctic conditions are not so hostile environment as cosmos and the high level of closure is not necessary for AEEAD. Therefore the structure of the Arctic Life Support System (ALSS) can be more simple and not so heavy, since there no needs to recycle all air inside.

By now the IBP SB RAS has developed new technologies for growing a variety of plants and technology to increase the closure of the substances flows if necessary.

> Increasing the density of phytoculture, which is important for practical applications.

$>$ Involvement of $\mathrm{NaCl}$ in the circulation of substances.

$>$ Involving inedible part of plants in the cycle through soil like substrate.

Additional reserves of growing plants technologies were identified and tested. For example, plant cultivation not on the plane, but in the volume is developed. The yield of plant products per unit area increases to 1.5-2 times (Fig. 3). One of the unresolved problems in BIOS-3 experiments was $\mathrm{NaCl}$ recycling. By now very perspective technology providing involvement of $\mathrm{NaCl}$ in intrasystem mass transfer is developed (Balnokin et al., 2010) on the base of edible saline species Salicornia europaea.

The original physicochemical method of oxidation of organic wastes has been developed in IBP SB RAS. Unlike the known physicochemical methods of organic oxidation, this method does not require high temperatures and pressures, as well as massive energy-intensive equipment (Kolyagin et al., 2013).

\section{The use of autonomous energy sources}

There are several projects of mobile nuclear power stations (https://helionews.ru/62595), which can be used for northern settlement. Nuclear reactor provides the highest level of autonomy including independence of weather and climate factors. However it is of high cost, needs protection from radiation, and is potentially dangerous for environment.

While solar energy in the North can be used only in the summer, wind energy is available practically all year round. Estimates show that the reserves of available wind energy cover 25 times the current energy consumption of mankind. However the direct use of wind energy is almost impossible due to its huge porosity - 


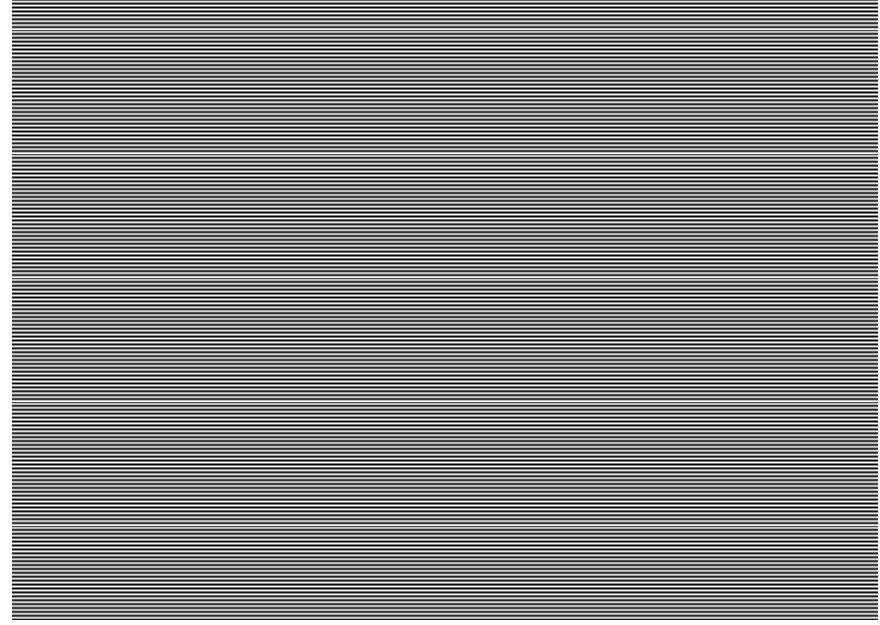

Fig. 3. Growth of tomatoes on a multi-necked vertical hydroponic installation. Vegetative phase (left) and reproductive phase (right)

temporal heterogeneity. So even with averaging over an interval of 30 days there are power fluctuations from 21 percent to 216 percent tenfold. Consequently there is a problem of autonomous provision of AEEAD with electric power of constant guaranteed power in the case of fundamental instability of its natural source.

This problem can be solved with energy storage batteries, which for practical (commercial) use should have high durability, high reliability and be of low cost. At once we shall exclude from consideration silver-zinc, lithium-polymer and similar accumulators because of their high cost and/or fire hazard. For example, consider the block of serial leadacid batteries GPL 121000, with a capacity of $1 \mathrm{~kW}^{*}$ month. Its cost is $\sim \$ 170000$. At the same time, the cost of electric energy stored for 10 years (guaranteed lifetime of this battery) is $\sim \$ 4000$, i.e. 42 times cheaper than batteries.

Beacon Power proposes to store energy in the form of kinetic energy of massive flywheels rotating at high speed (Kompaneets, 2010). Massive flywheels made of carbon fiber with a diameter of 1 meter rotate at a speed of 16000 revolutions per minute - the speed at the surface of the disk is about 2 Mach. Each device developed by the company weighs about 3.6 tons and is capable of delivering $100 \mathrm{~kW}$ of power for 15 minutes. We must immediately note the rather high complexity in the manufacture of this device and the relatively low density of the stored energy $\sim 7 \mathrm{~W} * \mathrm{~h} / \mathrm{kg}$. For comparison, the energy density of suggested thermal batteries using a basalt as a heat-consuming medium is $\sim 93 \mathrm{~W} * \mathrm{~h} / \mathrm{kg}$.

Accumulation in a heated stone is known and widely tested since ancient times, and is also used in modern alternative energy. For example, patent RU2027119 (Ayrapetyan, Zakaryan, 1992) proposed a thermal storage of solar energy using as a heat-consuming medium a rock, incombustible solid waste, and open rock of the mining industry. But the drawback of the traditional schemes is the considerable changes of the operating conditions of the heat engine in time.

The basic idea of the new approach to highheat accumulator design is that the heat-storage material with structurally complex system of thin tubes of the heat exchanger represents a "macro-composite", which properties can differ significantly from the properties of simple medium with thermal diffusion. With the proper 
structure of the heat exchanger tubes we can achieve much better performance than in the case of simple rapid heat exchange of the coolant in tubes with a heat-storage medium.

Theoretically, the following can be achieved:

- almost zero heat loss in the absence of thermal insulation;

- a significant stabilization of the temperature at the output of the thermal battery, and hence at the input of the heat engine, over the whole period of the discharge of the battery.

Suggested active heat protection based on an active countercurrent along the temperature gradient gives the possibility significantly reduce the volumes and cost of heat-insulating materials. This approach is promising if the task of the thermal battery is to smooth incoming energy. It means the initial energy is characterized by a high duty cycle, but the payload is fairly stable and never falls to zero.

Stabilization of output temperature is obtained due to the heat exchanger tubes are arranged perpendicular to the average temperature gradient. With low thermal conductivity and substantial active heat transfer the temperature field begins to move in a manner similar to the flow of slowly mixing liquids - the boundary of the hot and cold zones is blurred out slowly - it allows stabilizing the temperatures at the output of the system. The formula for the efficiency of the cycle of the complete discharge of the thermal battery was obtained:

$$
\eta=1-\frac{T_{c}}{\left(T_{h}-T_{c}\right)} \ln \left(\frac{T_{h}}{T_{c}}\right),
$$

where $T_{h}$ and $T_{c}$ are the temperatures of the heater and the refrigerator, respectively.

In the field of low efficiency (small ratios of the temperature of the thermal battery to the temperature of the refrigerator), the efficiency of the thermal battery is about half the efficiency of the ideal heat engine, and then the relative gap decreases.

\section{General scheme and evaluation}

of the parameters of the macrocomposite thermal battery system - a thermal engine

The scheme of the system as a whole is presented on Fig. 4. The charge-discharge

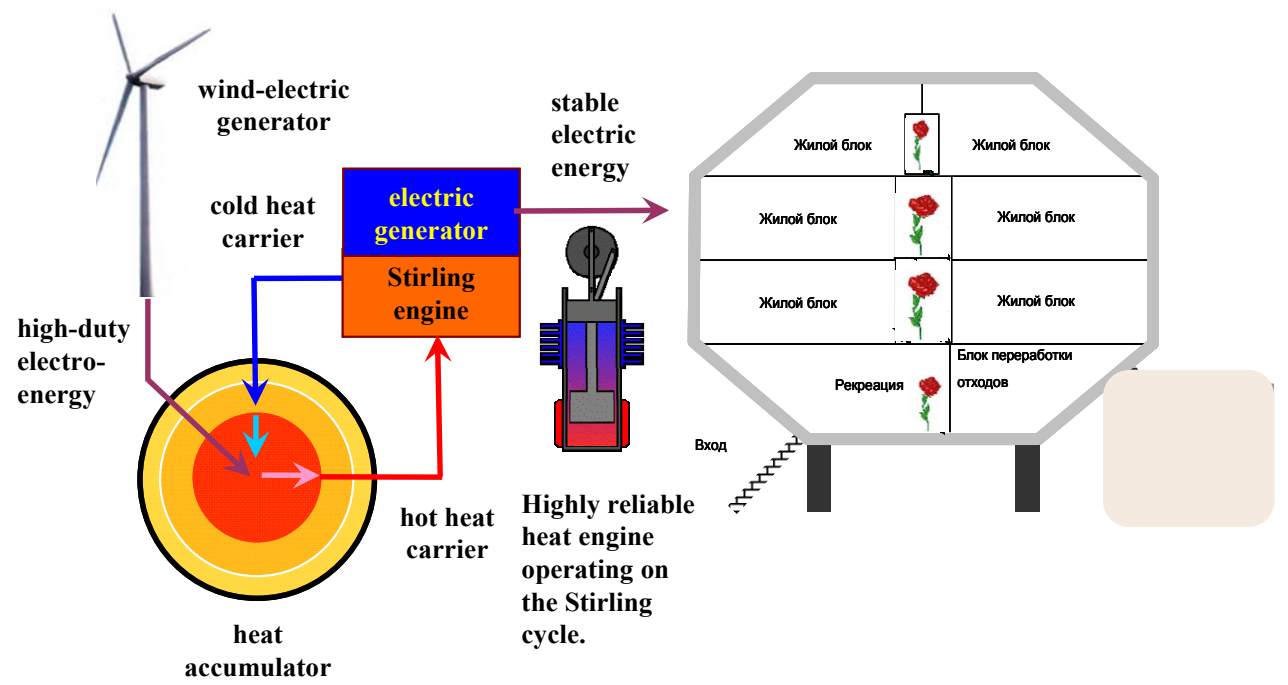

Fig. 4. General scheme of Arctic Ecological-Energy Autonomous Dwelling 
processes of the battery are unleashed with the processes of generating electricity. When charging a hot heat carrier enters the central zone of the battery, and a relatively cold one goes for heating, when discharging the heat carrier moves in the opposite direction.

In the $19^{\text {th }}$ century, engineers wanted to create a safe replacement for steam engines of that time, whose boilers often exploded because of high vapor pressures. A good option appeared with the invention of the Stirling engine (Rider, Huper, 1986). The main principle of the Stirling engine is the constantly alternating heating and cooling of the working body in a closed cylinder.

The advantages of the Stirling engine, which determine its use in conjunction with the macro-composite heat accumulator are: 1) Stirling engine can operate from almost any temperature drop; 2) the design of the engine is very simple; 3 ) simplicity of design provides unprecedented reliability in tens and hundreds of thousands of hours of continuous operation; 4) Stirling has no exhaust and does not have any parts or processes that can contribute to environmental pollution.

As an example, we calculated the mass and volume of basalt based thermal battery. Let's assume the system is required to supply $60 \mathrm{~kW}$ of useful power within two weeks. Based on tabulated data on the heat capacity of basalt and using the formulas for calculating the operating conditions, we conclude that the basalt mass should be 255 tons and the volume of $85 \mathrm{~m}^{3}$. This volume corresponds, for example, to a cylinder with a diameter and a height of about five meters. The mass of equipment which has to be delivered to the place (heat exchanger tubes, coolant, pumps) is only about 2 tons.

\section{Conclusions}

The concept of the Arctic EcologicalEnergy Autonomous Dwelling allows in principle to solve problems associated with mass development of the Arctic. There are theoretical and experimental developments supporting this concept: optimal ecological house layouts for the Arctic; preliminary selection of plants for indoor greenhouses; systems of organic wastes decomposition; calculations of heat exchange and lighting modes for northern houses; optimal arrangements of ecological cottages and apartment buildings. Suggested concept allows Arctic mastering with minimal disturbance of vulnerable Arctic ecological systems.

\section{References}

Ayrapetyan S.A., Zakaryan G.A. (1992) Thermal accumulator of energy. Patent of Russian Federation RU2027119, 1992.07.27

Balnokin Y., Myasoedov N., Popova L., Tikhomirov A., Ushakova S., Lasseur Ch., Gros J.-B. (2010) Use of halophytic plants for recycling $\mathrm{NaCl}$ in human liquid waste in a bioregenerative life support system. Advances in Space Research, 46: 768-774

Fedoseev A. (2013) Doctrinal views of the US and Canada on the development of the Arctic. Foreign Military Review, 6: 3-9

Gitelson J.I., Okladnikov Yu.N. (1994) Man as a component of a closed ecological life support system. Life Support \& Biosphere Science, 1(2): 73-81

Gitelson I.I., Kovrov B.G., Lysovsky G.M., Okladnikov Y.N., Rerberg M.S., Syd'ko F.Ya., Terskov I.A. (1975) Experimental ecological systems including humans. Problems of space biology, Vol. 28. Moscow, Nauka, 312 p. 
Kapfhammer H.P. (2003) Sick building syndrome or fungal allergy? When houses cause illness. MMW-Fortschritte der Medizin, 145(33-34): 26-30

Kolyagin G.A., Kornienko V.L., Tikhomirov Yu.A., Trifonov S.V. (2013) Electrosynthesis of hydrogen peroxide from oxygen in a gas diffusion electrode in solutions of mineralized exometabolites. Electrochemistry, 49(10): 1120-1124

Kompaneets A. (2010) Flywheel as a store of excess energy. http://facepla.net/index.php/the-news/ energy-news-mnu/580-flywheel-power-grid-storage-project

Mendell M.J. (1993) Non-specific symptoms in office workers: a review and summary of the epidemiologic literature. Indoor Air, 3: 227-236

Rider G., Huper Ch. (1986) Stirling engine. Moscow, Mir, 464 p.

Shahzad S.S. (2016) Building-related symptoms, energy, and thermal control in the workplace: personal and open plan offices. Sustainability, 8: 331

Sick Building Syndrome, Environmental Health Center, National Safety Council, June 18, 1997. URL: http://www.nsc.org/ehc/indoor/sbs.htm

Zweers T., Preller L., Brunekreef B., Boleij J.S.M. (1992) Health and indoor climate complaints of 7043 office workers in 61 buildings in the Netherlands. Indoor Air, 2: 127-136 